\title{
On-Line Thermal Barrier Coating Monitoring for Real- Time Failure Protection and Life Maximization
}

\author{
Semi-Annual Progress Report \\ Reporting Period Start Date: April 2003 \\ Reporting Period End Date: September 2003
}

Prepared for:

U.S Department of Energy

National Energy Technology Laboratory

P.O. Box 10940

Pittsburgh, PA 15236-0940

Cooperative Agreement No. DE-FC26-01NT41232

Prepared by:

Dennis H. LeMieux

Siemens Westinghouse Power Corporation 4400 Alafaya Trail Orlando, Florida 32826

October 2003 


\section{Disclaimer}

This report is an account of work sponsored by an agency of the United States Government. Neither the United States Government nor any agency thereof, nor any of their employees, nor Siemens Westinghouse Power Corporation make any warranty, express or implied, or assumes any legal liability or responsibility for the accuracy, completeness, or legal fullness of any information, apparatus, product, or process disclosed, or represents that its use would not infringe privately owned rights. Reference, herein, to any specific commercial product, process, or service by trade name, trademark, manufacturer, or otherwise does not necessarily constitute or imply the endorsement, recommendation, or favoring by the United States Government or any agency thereof. The views and opinions of authors expressed herein do not necessarily state or reflect those of the United States Government or any agency thereof. 
$\begin{array}{lll}1.0 & \text { Abstract } & 4\end{array}$

$\begin{array}{lll}2.0 & \text { Introduction } & 5\end{array}$

$\begin{array}{lll}3.0 & \text { Executive Summary } & 6\end{array}$

4.0 Task 2: Develop On-line TBC Monitor for Blades $\quad 7$

4.1 Subtask 2.1 Statement of Work: Determine Temperature-Dependent
IR Characteristics of Blade Surface and GT Working Fluid

$\begin{array}{lll}\text { 4.1.1 } & \text { Progress since last reporting period } & 7\end{array}$

$\begin{array}{lll}4.1 .2 & \text { Conceptual Design and configuration } & 8\end{array}$

$\begin{array}{ll}\text { 4.1.4 Thermal Barrier Coating Emittance Measurements } & \mathbf{8}\end{array}$

4.1.5 Infrared Camera Experiments $\quad 9$

5.0 Task 3: Develop On-line TBC Monitor for Vanes 9

$\begin{array}{lll}5.1 & \text { Experiments } & 10\end{array}$

$\begin{array}{lll}5.2 & \text { Results and Discussion } & 10\end{array}$

$\begin{array}{lll}\text { 5.2.3 Conclusion of Plate test performed } & 11\end{array}$

6.0 Task 4: Develop TBC Remaining Life Prediction Model 11

6.1 Experiments 12

6.1.1 Status of TBC Remaining Life Prediction Model 12

6.1.2 Results 13

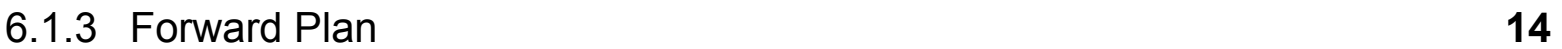

$\begin{array}{lll}7.0 & \text { Conclusion } & 14\end{array}$

8.0 Key Milestone Update $\quad 14$

$\begin{array}{lll}9.0 & \text { Program Status } & 14\end{array}$

$\begin{array}{lll}10.0 & \text { Status of Milestones } & 15\end{array}$

11.0 Milestone completion, 2002

12.0 Milestone completion, 2003

List of Images

Image 1

Image 6 


\section{ON-LINE THERMAL BARRIER COATING MONITORING FOR REAL-TIME FAILURE PROTECTION AND LIFE MAXIMIZATION}

\section{0 - ABSTRACT}

Under the sponsorship of the U. S. Department of Energy's National Energy Laboratory, Siemens Westinghouse Power Corporation proposes a four year program titled, "On-Line Thermal Barrier Coating (TBC) Monitor for Real-Time Failure Protection and Life Maximization," to develop, build and install the first generation of an on-line TBC monitoring system for use on land-based advanced gas turbines (AGT).

Federal deregulation in electric power generation has accelerated power plant owner's demand for improved reliability, availability, and maintainability (RAM) of the landbased advanced gas turbines. As a result, firing temperatures have been increased substantially in the advanced turbine engines, and the TBCs have been developed for maximum protection and life of all critical engine components operating at these higher temperatures. Losing TBC protection can, therefore, accelerate the degradation of substrate component materials and eventually lead to a premature failure of critical components and costly unscheduled power outages. This program seeks to substantially improve the operating life of high cost gas turbine components using TBC; thereby, lowering the cost of maintenance leading to lower cost of electricity.

Siemens Westinghouse Power Corporation has teamed with Indigo Systems, a supplier of state-of-the-art infrared camera systems, and Wayne State University, a leading research organization in the field of infrared non-destructive examination (NDE), to complete the program. 


\section{0 - INTRODUCTION}

The objective of this proposed work is to design, build, and install a gas turbine blade and vane TBC monitor that will monitor, in real time, during turbine operation, the formation and progression of critical TBC defects. The monitor will track and report on the progression of TBC defects, estimate remaining TBC life, and notify operations of impending damage. The program goal is to alleviate unscheduled outages due to TBC failure and engine damage by having a monitor system to assure that irreversible damage does not occur.

The four year program, as managed by Siemens Westinghouse, will begin with a combined effort by our Design Engineering, Materials Engineering, Diagnostics, and Advanced Sensors groups, together with Indigo Systems to develop the conceptual design for the monitor. Blade and Vane monitors, based on our preliminary work, will then be designed and built by Indigo Systems and Siemens Westinghouse's Advanced Sensors group. Although blade and vane monitor tasks will start at the same time, the blade monitor will slightly lead the vane monitor due to the relative maturity of the concept. Once the sensor designs are complete, the advisory system will be designed to incorporate the sensor and TBC remaining life model inputs. Once all systems are built, they will be installed on an engine that is operated by Siemens Westinghouse. The monitor will be operationally tested on a relevant gas turbine engine at a selected site.

The project is defined along six major technical tasks including:

Task 1: Conceptual Design of System Configuration and Definition

Task 2: Develop On-line TBC Monitor for Blades

Task 3: Develop On-line TBC Monitor for Vanes

Task 4: Develop TBC Remaining Life Prediction Model

Task 5: Develop Artificial Intelligence (AI)-based Supervisory System

Task 6: Field Trials

This report summarizes results from these tasks. 


\section{0 - EXECUTIVE SUMMARY}

Under the sponsorship of the U. S. Department of Energy's National Energy Laboratory, Siemens Westinghouse Power Corporation proposes a four year program titled, "On-Line Thermal Barrier Coating (TBC) Monitor for Real-Time Failure Protection and Life Maximization," to develop, build and install the first generation of an on-line TBC monitoring system for use on land-based advanced gas turbines (AGT).

Federal deregulation in electric power generation has accelerated power plant owner's demand for improved reliability, availability, and maintainability (RAM) of the landbased advanced gas turbines. As a result, firing temperatures have been increased substantially in the advanced turbine engines, and the TBCs have been developed for maximum protection and life of all critical engine components operating at these higher temperatures. Losing TBC protection can accelerate the degradation of substrate component materials and eventually lead to a premature failure of critical components and costly unscheduled power outages. This program seeks to substantially improve the operating life of high cost gas turbine components using TBC; thereby, lowering the cost of maintenance leading to lower cost of electricity.

Siemens Westinghouse Power Corporation has teamed with Indigo Systems; a supplier of state-of-the-art infrared camera systems, and Wayne State University, a leading research organization in the field of infrared non-destructive examination (NDE), to complete the program.

The anticipated benefits are listed below:

(1) Use of the on-line TBC monitor will significantly improve plant reliability and availability by extending critical component lives. Damaged TBC can be identified early and repaired before the component's catastrophic failure.

(2) Use of the on-line TBC monitor will significantly increase availability of peaking gas turbines by eliminating down time required for frequent borescope examination of TBC's.

(3) The on-line TBC monitor can be used on all existing and new gas turbines that use TBC to protect critical turbine parts. The fundamental concepts of the online TBC monitoring is equally applicable to smaller land, aero and marine based gas turbines. This opens future global market opportunities for the team to pursue.

(4) The financial payback of this technology comes in the form of reduced maintenance costs and having power plants available when they would not have been. All of today's advanced gas turbines can benefit from this monitor. We expect over 600 "F" and "G" class gas turbines to be in service over the next 12 years. The total estimated 12-year life-cycle maintenance cost savings for these $600+$ units is expected to be over $\$ 600 \mathrm{M}$. 


\section{0 - TASK 2: DEVELOP ON-LINE TBC MONITOR FOR BLADES}

The objectives for Row 1 TBC vane coating monitor is to detect TBC coating degradation of the hottest location in the expander to provide an early warning for degradation of TBC coating in the hot gas path. Monitoring information from the Row 1 vane will also be integrated into TBC lifing models to allow outage planning and maximization of availability.

\section{1- SUBTASK 2.1 STATEMENT OF WORK}

\section{DETERMINE TEMPERATURE-DEPENDENT IR CHARACTERISTICS OF BLADE SURFACE AND GT WORKING FLUID}

2.1.1 Measure Spectroscope Properties of GT Working Fluid: Infrared transmission, absorption, and emissivity properties of the turbine engine atmosphere will be determined within the range of operating parameters expected. The highpressure, high-temperature, high-velocity gas will effect the relationship between radiance and temperature as will the TBC damage.

2.1.2 Measure TBC Coated Blade Emissions as Function of Temperature: Thermal emission characteristics will be determined for several states of the TBC condition. They will include sintering, contamination and defect formation. Characteristics of deteriorating TBCs will be studied. Deteriorating TBC emissions will demonstrate a local step change in emissivity.

2.1.3 Characterize Emissions from TBC Defects (APS): Emissions from critical TBC defects types will be determined. Debond growth and surface temperature changes will influence the radiance and radiant transients. The debond is expected to cause an increase in the absolute temperature of the TBC surface. As the same debond grows, the temperature will increase and the imaged region of the spallation will grow. Basic measurement capabilities will be investigated by building a laboratory model of the TBC blade sensor.

\subsection{1- PROGRESS SINCE LAST REPORTING PERIOD}

\section{SUBTASK 2.2 DEVELOP IR MONITOR FOR TBC COATED BLADES}

This subtask consists of the following components: (1) select/develop IR sensors; (2) determine data types, transmission rate, and formats, (3) design data analysis scheme for the GT-TBC monitor inputs, (4) determine control interface and blade sensor attachment, and (5) develop blade surface condition monitor.

The array detector will be a state-of-the-art, cooled, solid state, infrared detector. Work conducted in Task 1 shall determine the best combination of atmospheric spectral window and maximum TBC system information. Once determined, the detectors will be designed within these spectral windows. The detector spectral selection used for embodiment 2 shall have the additional consideration of optic transport. The optic 
system must be rugged in the AGT environment and allow remote detector location outside of the AGT enclosure, if possible. The optic device shall be designed to allow replacement of the fiber bundles, including gas-exposed viewing optics without disassembling any AGT components. The closest location for detector installation is outside of the shell of the turbine. Future embodiments may allow complete gas path viewing optics and detector replacement without shutting the turbine down, an internally installed optical directly involved in this activity. Design Engineering has determine the optimum sensor vantagepoints with the following considerations: pressure boundary control, serviceability, viewing optics protection, critical region viewing, viewing regions, and sensor installation minimization. This activity has establish guidelines and limitations for sensor type, placement and attachment. The Program Manager along with SWPC Design Engineering will publish an installation requirement complete with specifications, attachment requirements, and modified and approved AGT drawings demonstrating penetrations and detailed pressure boundaries. They will be responsible for approving all sensor attachments and installation procedures.

\subsection{2 - CONCEPTUAL DESIGN AND CONFIGURATION}

The conceptual design will allow the implementation of the concept to more thoroughly assess practical issues of the sensors implementation and cost. Along with the conceptual design as viewed in Image 1, some additional verification tests or analysis will be performed on the concept to allow a better assessment of the monitoring system. Dual high-speed infrared cameras will operate with a spectral response of $0.9-1.65 \mu \mathrm{m}$ and $3-5 \mu \mathrm{m}$ and integration or shutter speed on the order of 3 microseconds. These cameras with a blade position sensor will allow viewing of a single blade surfaces during engine operation. Both systems have state-of-the-art real-time infrared (IR) sensors that captures images on the blades rotating at $3600 \mathrm{rpm}$ which is equivalent to $400 \mathrm{~m} / \mathrm{s}$ linear speed.

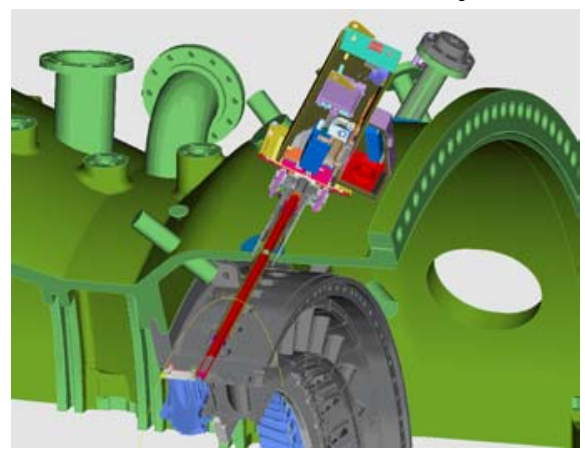

Image 1

\subsection{4 - THERMAL BARRIER COATING EMITTANCE MEASUREMENTS}

Currently, to date, the program task objectives have identified the emittance of clean 8SYZ air plasma sprayed (APS) TBC. The results of the emissivity measurements demonstrate a broad variation of the level of total emissivity. Temperature measurements would be more accurate in the long wavelength infrared (LWIR) where ceramic TBC emissivities are typically high and stable. Clean TBC in Gas turbine engine have demonstrated low, variable emissivities at short wavelengths, which could lead to serious temperature measurement inaccuracies. As the laboratory tests continue a clearer picture is emerging in regard to the defect contrast characteristics of thermal barrier coatings (TBC) for both cameras. Further testing has confirmed that the maximum peak contrast for defect detection occurs in the Near Infrared (0.9 $1.65 \mu \mathrm{m})$. The results from these experiments are described in report 1 from Advance Fuel Research, Emittance Measurements for Siemens-Westinghouse Lifting TBC. 
Appendix 4, Report 1 profiles the spectral emittance of clean APS thermal barrier coating as a function of temperature vs. spectral response.

\subsection{5 - INFRARED CAMERA EXPERIMENTS}

Experiments have validated two mechanical design drawing, 3D models and design reviews profiling the penetration and viewing of the turbine to row 1 blades. The criticality ranking of all blade regions, accessibility of blade surfaces, and propensity for degradation for blade surfaces were reviewed and analyzed to determine critical surfaces to be monitored. Testing and analysis, at the Siemens Gas Turbine Manufacturing facility in Berlin, Germany have validated 2 high-speed infrared cameras from Indigo Systems. The validated infrared cameras operated in the infrared spectrum from $0.9-5 \mu \mathrm{m}$. The infrared cameras demonstrated high-speed shutter

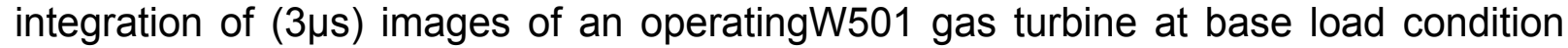
while view row 1 blades. The row 1 tip speed works out to be $387.422 \mathrm{~m} / \mathrm{sec}$. This means that for a nominal integration time of $3 \mathrm{uS}$, the blade tip would travel $1.16 \mathrm{~mm}$, or about 0.046 inches. This equals about 867 miles per hour. The blade monitor when implemented in phase 2 will provide a radiance profile map of a functioning first row turbine blades. Modeling of TBC failure modes and field testing of the Monitoring system remain to be completed.

\section{0 - TASK 3: DEVELOP ON-LINE TBC MONITOR FOR VANES}

\section{Program Proposal}

The objectives for Row 1 TBC vane coating monitor is to detect TBC coating degradation of the hottest location in the expander, and to provide an early warning for degradation of TBC coating in the hot gas path. Monitoring information from the Row 1 vane will also be integrated into TBC lifing models to allow outage planning and maximization of availability. In order for the Row 1 Vane monitor to meet these objectives, it will need to have the following criteria:

- The monitoring system should be capable of providing real-time data, and the sensors should have life capability in excess of normal outage times at operating conditions.

- The monitor will need to be an early indication of TBC coating condition changes.

- The monitor will need to monitor the vane globally so that deterioration of particular areas of the vane will be detected.

- The distribution of sensors must be minimized to avoid installation and operational complication.

- The monitor will need to be sensitive to subtle changes in TBC coating conditions.

- Preferably the monitor should be dependent on sensing the condition of the TBC, regardless of the cause of the deterioration. Detection of foreign object damage, as well as temperature damage, will be important.

There are no current sensors that meet all of the above criteria. Mature techniques for sensing (e.g., thermocouples) can be used to locally detect Row 1 vane problems, at least after the problem advances to the point where damage has occurred in the TBC 
coating and the vane. This program will evaluate some emerging technologies for potential application to this problem. At the same time, mature technologies will be used as a back up in the testing, serving to baseline the interpretation of the TBC coating life sensing system. The result of the program will be the development of a vane TBC coating life detection system that incorporates the state-of-the art methods of detecting coating failures.

\section{1 - EXPERIMENTS}

\section{Plans for Second Level Down Selection}

Based on the six desired objectives for the vane sensor, we have reduced the candidates under investigation from the initial ten, to the most likely five. These down selected candidates were described and reported in previous reporting period. The conceptual design will allow the implementation of each concept to more thoroughly assess practical issues of the sensors implementation and cost. Along with the conceptual design, some additional verification tests or analysis will be performed on each sensor concept to allow a better assessment of the sensor's promise. The following sensor has been chosen for most likely success for vane monitoring.

\section{2 - RESULTS AND DISCUSSION}

\section{Selected Sensor: Acoustic Waveguide (AWG)}

\section{Status of Preliminary Testing:}

1. Laboratory tests indicate that an AWG can launch slow $(1900 \mathrm{~m} / \mathrm{sec})$ moving surface waves through thermal barrier coatings (TBC) and the coating considerably damps (reduces the signal level) of the transmitted wave. In an experiment with 10 $\mathrm{cm} \times 15 \mathrm{~cm}$ Hastelloy X plates, one of bare metal, and one coated with a 20 mil thick layer of air plasma sprayed (APS) TBC, the coating reduced the transmitted signal level by 10 times. This should be helpful when AWG are used for interrogating the condition of gas turbine vanes and parts.

2. Field tests carried out on a "V" machine in Berlin demonstrated that an acoustic signal could be transmitted via an AWG about 2 meters inside a machine, pass through a vane, and be returned via another AWG to be measured outside the machine. The return signal was characteristic of laboratory measurements and therefore we believe capable of providing real-time condition data when the technique is properly refined. Also, after several test runs of the machine, the AWG was still intact.

Planned Tests Status: Laboratory tests are examining specimens with varying amounts of TBC to determine expected signal responses to simulated vane TBC flaws.

\section{Thermal Barrier Coating Acoustic Damping}

As the laboratory tests continue a clearer picture is emerging in regard to the acoustic characteristics of thermal barrier coatings (TBC). Further testing has confirmed that an air plasma sprayed TBC will damp (10 to 1) acoustic surface waves, but only under impact (or FOD type conditions) and with the acoustic waveguide used in receive or listening mode. This damping does not apply under transmit/receive conditions as 
reported earlier from preliminary tests, but will be present due to pressure pulses generated as blades pass vanes.

\section{$\underline{\text { Response of Thermal Barrier Coating to Simulated Vane Flaws }}$}

Tests are now underway using $10 \mathrm{~cm}$ x 15cm Haynes 230 (NiCrAlloy) plates of bare metal, one with a 20mil thick layer of air plasma sprayed (APS) TBC, and other TBC plates with one centimeter wide slots cut in the TBC to simulate spalling. Preliminary results using the AWG sensors in the transmit/receive mode indicate that the TBC transmits much larger (5 to 1 ) levels than bare metal. Also, the transmitted signal level changes considerably (5 to 1 ) as the number of slots in the TBC increases from one to five. Although all aspects of the acoustic surface wave transmission are not fully understood as yet, it does appear that TBC spalling (simulated by slots) should be detectable.

\section{Acoustic Isolation of AWG Inside Gas Turbine Engine}

With the "V" engine, a 6mm-diameter stainless steel capillary tube was tack welded at various locations within the engine (from the exit to a vane location). The AWG was inserted within the tubing for protection and acoustic isolation. This system performed well, and even though the AWG touched the tube wall at various locations, the acoustic isolation from the capillary tubing to AWG, was around 100 to 1 . This design is being used for the FD engine but for certain vane locations, $4 \mathrm{~mm}$-diameter capillary tubing was required. Laboratory tests were performed with the AWG within both $4 \mathrm{~mm}$ and $3 \mathrm{~mm}$ diameter capillary tubing (the AWG diameter is $1 \mathrm{~mm}$ ). It was found that the acoustic isolation for the $4 \mathrm{~mm}$ tubing was 10 to 1 (acceptable for the FD tests) while the $3 \mathrm{~mm}$ tubing had little acoustic isolation.

\subsection{3 - CONCLUSION OF PLATE TEST PERFORMED.}

1.Acoustic Wave Guide (AWG) technology is in the very early stages of development.

2. The AWG research conducted at STC proved to be inconclusive with the techniques used by the group, thus the results presented at the peer review meeting did not reach the expectations that were originally anticipated.

3. Since Siemens is the leader in research activities with AWG technology, it was recommended that alternate methods and techniques be explored in order to best utilize the potential of this emerging technology.

\section{0 - TASK 4: DEVELOP TBC REMAINING LIFE PREDICTION MODEL}

\section{PROGRAM PROPOSAL}

The objectives of task 4 are (1) monitor failure progression of TBC's under high heat flux conditions and (2) develop a numerical model to describe the failure progression as a function of the loading regime. 


\section{1 - EXPERIMENTS - SUBTASK 4.1 CONDUCT HIGH HEAT FLUX TESTS FOR MONITORING TBC FAILURES}

The high heat flux testing rig (HHFTR) at Westinghouse Plasma Corporation (WPC), Madison, PA will be upgraded to allow monitoring of failure progression under engine-like temperature conditions. The NDE monitoring device proposed in the program to evaluate TBC reliability during engine service will be incorporated on a sub-scale level into the test chamber of the available test rig. WPC has a unique world-class facility for testing coated samples in a thermal fatigue-thermal gradient.

A tubular specimen with APS thermal barrier coating is subjected to the high heat flux with active cooling. A uniform surface temperature of $>1350^{\circ} \mathrm{C}$ will be maintained at the thermal barrier coating outer surface. A large temperature gradient across the TBC layer will be created such that the TBC-to metal interface temperature is held at $<1000^{\circ} \mathrm{C}$ while the outer surface is at the high temperature mentioned above. A cyclic operation with heating cycle duration's of 3 minutes to $>8$ hours can be achieved. The monitoring device will capture the TBC failure progression during testing period. Thereby, it is able to detect and quantify delamination as well as vertical crack growth.

\subsection{1 - Status of TBC Remaining Life Prediction Model:}

The objectives of task 4 are (1) monitor failure progression of TBC's under high heat flux conditions (Subtasks 4.1) and (2) develop a numerical model to describe the failure progression as a function of the loading regime.

Subtask 4.1 Conduct high heat flux tests for monitoring TBC failures

Previous monthly reports dated 10/31/02 have been reported the use of the high heat flux testing rig (HHFTR) at Westinghouse Plasma Corporation (WPC), Madison, PA. New technical information per Stefan Lampenscherf of Siemens Westinghouse is outlined with the initial background and approach.

Members of the On-Line TBC Monitoring Team traveled to Germany to validate a new High Heat Flux Test Rig (HHFTR) based on Stefan Lampenscherf's recent analysis. The facility would have to support this type of failure. Key results of Stefan's load analysis were:

- High TBC surface temperatures $\left(\mathrm{T}_{\mathrm{TBC}}>1300 \mathrm{C}\right)$ does not result in failure initiation and propagation at the bond coat/TBC interface. This is due to a lower loading condition for $\mathrm{T}_{\mathrm{TBC}}>\mathrm{T}_{\mathrm{BC}}$

- At $\mathrm{T}>1300 \mathrm{C}$, failure is predominantly in the TBC. Therefore, establishing a lifing model or propagation of a spall by testing at $T>1300 \mathrm{C}$ would not represent the same mechanism as observed under engine conditions

- Consequently, financially the testing at Waltz Mill, for online monitor effort, are not justified 
Tests performed at Forschungszentrum Juelich, Julich Research Facility during April 2003 validated the test rig and facility for the functionality of the image acquisition system for TBC Lifing Numerical Model. The objectives for the test validation in Julich, Germany were:

- Validate Vassen rig for TBC Lifing Model

- Current testing considerations

- Validate infrared instrumentation

- Measure radiance rate of change from artificial defect samples

- Measure quantitative surface temperatures

- Detection of possible prespallation event

- Determine type of data to be extracted from lifing test.

The results of the testing in Germany would provide a time, temperature and radiance change of the progression of the TBC samples. The samples of the tests were 15 buttons per PD specifications as used for the Row $1 \mathrm{~F}$ blades and 1.5 inches in diameter, Bond coated and heat treat. The Air Plasma Sprayed (APS) TBC top consisted of nominally 12 mils coating thickness and surface finish per spec. , and a artificial defect was created between the bond coat and TBC to produce a simulated spalled defect area in the material. These test specimens are seen in image 6 .

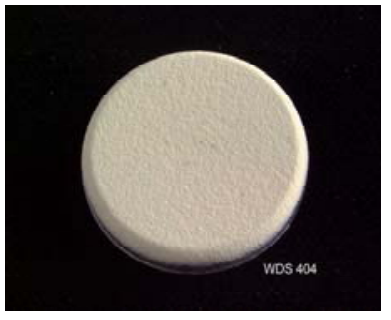

Image 6

The testing used three infrared cameras that total ranged in the infrared which measured and monitored from nominally from $0.9-14 \mu \mathrm{m}$. The follow are some of the analysis from the Near Infrared camera for the test results of the new facility and test rig.

\subsection{2 - Results Examples}

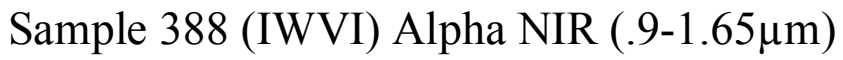

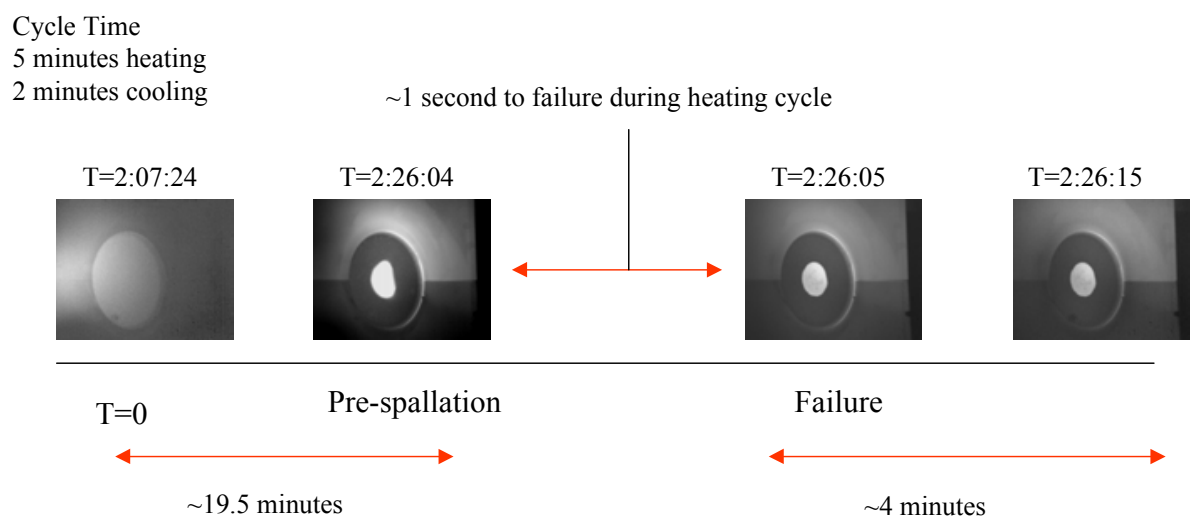




\subsection{3 - TBC LIFE PREDICTION FOR ON-LINE MONITOR PROGRAM - FORWARD PLAN}

- Additional lifing related information that may be required to proceed for selection of test conditions/facility.

- Additional detailed discussions with are scheduled to discuss initial calculations and additional progress.

- Specimen geometries and approach to be finalized.

\section{0 - CONCLUSION}

The On-line TBC monitoring program has taken an aggressive approach to develop and install a real-time monitor for both blades and vanes. The program continues to meet and/or exceed the milestone and budgetary requirements. As reported, Siemens Westinghouse engineers have detailed a procedure to penetrate and install a spectral relay-imaging instrument to measurement the radiance, in realtime, row 1 blades. The radiance is relayed through the imaging tube and onto the focal plane array of the high-speed infrared camera operating with a spectral response of .9-5.0 microns. The emittance of clean TBC in the short infrared is very reflective, with longer infrared near black body emittance. The contrast in short wave provides the greatest contrast between the TBC coating and bond coat interface. This contrast provides radiance change information to monitor the progressive growth and spallation between these two interfaces. Additional tests next quarter (YR04) will determine the remaining life probability for the On-line numerical model. The On-line TBC Vane Monitor continues with the final downselection, thus being the Acoustic Wave-Guides. Tests have indicated this sensor can be installed with minimal sensors and wires, very sensitive to TBC loss, and independent of geometry.

The design and assembly of the blade monitoring system will allow viewing of row 1 blades from a radial oblique viewing direction. The monitoring systems will be installed during (Phase 1) in a Westinghouse 501FD engine in Berlin FY03 and (Phase 2) long term LTP host site FY04 yet to be determined.

\section{0 - KEY MILESTONE UPDATE}

Current program milestones are on or ahead of schedule.

\section{0 - PROGRAM STATUS}

Achievements from 10/01/01-03/31/03

- DOW Proof-of-Concept Testing, November 2001 
-3D Model Scoping penetration location and direction, 3 of 4 models complete

- Westinghouse Plasma Center HHFTR Modification, Completion May 2002

- Spectroscopy measurements of GT working fluids, DOW Test, November 2001

- Purchase of NIR Infrared Data Acquisition system and rental agreement of Infrared camera head

- Siemens Westinghouse Power Corporation Program review, Completion March 28, 2002

- Select Infrared Hardware, Milestone completion April 2002

- Siemens Westinghouse Power Corporation Program review, Completion May 28, 2002

- Siemens Westinghouse Power Corporation Program review, Completion September 27, 2002

- R5 Design Review for Radial Penetration, Completion January 2003

\section{0 - Status of Milestones}

Current program milestones are on or ahead of schedule.

\section{0 - Milestone Completion, 2002}

- Develop Proof of Concept of Infrared Sensor, Complete 12/10/2001

- Select/Develop infrared sensors - The final selection for the core of the blade monitor, the focal plane array, Complete 3/12/02

- Conduct lab prototype experiments on selected vane sensors - The vane sensor elements and concept will be evaluated in a lab environment, Complete 8/30/2002

- Assess computer controls and software needs - This effort will complete the statement of computer and software needs anticipated to input, update and archive the data generated by both the blade and vane monitors. Complete $8 / 30 / 2002$

- Modify current high heat flux test rig - The High-Heat Facility rig test will be retrofit for Blade monitor simulation. Complete 6/6/2002

\section{0 - Milestone Completion, 2003}

- Characterize emissions from TBC defects (APS)-Infrared emission from TBC and associated progressions of deterioration will be characterized, I.E. debond growth, spall. 